\title{
Household environmental tobacco smoke and risks of asthma, wheeze and bronchitic symptoms among children in Taiwan
}

\author{
Ching-Hui Tsai ${ }^{1}$, Jiun-Hau Huang ${ }^{2}$, Bing-Fang Hwang ${ }^{3}$, Yungling $L L^{1} e^{1,4^{*}}$
}

\begin{abstract}
Background: Although studies show that maternal smoking during pregnancy increases the risks of respiratory outcomes in childhood, evidence concerning the effects of household environmental tobacco smoke (ETS) exposure remains inconsistent.
\end{abstract}

Methods: We conducted a population-based study comprised of 5,019 seventh and eighth-grade children in 14 Taiwanese communities. Questionnaire responses by parents were used to ascertain children's exposure and disease status. Logistic regression models were fitted to estimate the effects of ETS exposures on the prevalence of asthma, wheeze, and bronchitic symptoms.

Results: The lifetime prevalence of wheeze was $11.6 \%$ and physician-diagnosed asthma was $7.5 \%$ in our population. After adjustment for potential confounders, in utero exposure showed the strongest effect on all respiratory outcomes. Current household ETS exposure was significantly associated with increased prevalence of active asthma, ever wheeze, wheeze with nighttime awakening, and bronchitis. Maternal smoking was associated with the increased prevalence of a wide range of wheeze subcategories, serious asthma, and chronic cough, but paternal smoking had no significant effects. Although maternal smoking alone and paternal smoking alone were not independently associated with respiratory outcomes, joint exposure appeared to increase the effects. Furthermore, joint exposure to parental smoking showed a significant effect on early-onset asthma (OR, 2.01; 95\% $\mathrm{Cl}, 1.00-4.02)$, but did not show a significant effect on late-onset asthma (OR, 1.17; 95\% Cl, 0.36-3.87).

Conclusion: We concluded that prenatal and household ETS exposure had significant adverse effects on respiratory health in Taiwanese children.

\section{Introduction}

The reported prevalence of childhood asthma/wheeze is increasing around the world [1-4]. The changing pattern of these diseases has not been fully explained, in part because of an incomplete understanding of its pathogenesis. The change has been too rapid to be accounted for by changes in gene frequencies. It is also unlikely that it can be totally accounted for by changes in either clinical diagnostic patterns or increased recognition of respiratory symptoms by the general population [5]. This shift does, however, suggest a role for environmental exposures in the etiology of this evolving epidemic [6].

\footnotetext{
* Correspondence: leolee@ntu.edu.tw
${ }^{1}$ Institute of Preventive Medicine, College of Public Health, National Taiwan

* Correspondence: leolee@ntu.edu.tw
${ }^{1}$ Institute of Preventive Medicine, College of Public Health, National Taiwan University, Taipei, Taiwan
}

(c) 2010 Tsai et al; licensee BioMed Central Ltd. This is an Open Access article distributed under the terms of the Creative Commons Attribution License (http://creativecommons.org/licenses/by/2.0), which permits unrestricted use, distribution, and reproduction in any medium, provided the original work is properly cited.

It is estimated that around 1.3 billion people worldwide smoke [7], and the number is predicted to increase in the coming years as smoking rates continue to increase among youth, primarily among young girls [8]. Exposure to environmental tobacco smoke (ETS) is common in children and causes substantial morbidity [9-13]. Estimates of population attributable risk for household ETS exposure in children range from $9 \%$ for asthma prevalence to $25 \%$ for hospital admissions due to respiratory symptoms [13]. The World Health Organization estimates that approximately half of the children in the world are exposed to ETS, mostly in their homes [14]. In Taiwan, schoolchildren are not typically exposed in public due to the legislative ban on public smoking and regular health promotion campaigns; home exposure is likely the dominant source of ETS. It was 
reported that approximately $60 \%$ Taiwanese children under the age of 17 were exposed to household ETS [15], and therefore an estimated 3.3 million children were at risk for adverse health effects from this exposure.

Evidence of the effects of ETS exposure on childhood respiratory outcomes is inconsistent [16-22]. Although an effect for paternal smoking has been reported, exposure to maternal smoking has consistently had the strongest association with adverse respiratory health effects $[9,23]$. The strength of the association between maternal smoking and asthma/wheeze is in part due to larger ETS doses from maternal smoking than from other sources [24]. Although there is evidence that maternal smoking during pregnancy increases the risk of asthma/wheeze in childhood [11,25-27], the effects of in utero exposure on the occurrence of respiratory symptoms have not been extensively studied or compared with other household sources of ETS.

The Taiwan Children Health Study (TCHS) offers an opportunity to investigate the effects of household ETS exposure on the occurrence of respiratory symptoms in Taiwanese children. At cohort entry, we used lifetime tobacco smoke exposure histories to investigate the relationships of multiple sources of ETS exposure with parental-reported respiratory outcomes. The individual and joint effects of parental smoking habits were also examined for associations with early-onset and late-onset childhood asthma.

\section{Methods \\ Study design}

The Taiwan Children Health Study (TCHS) has a multipurpose nationwide design, and is focused on common environmental factors such as outdoor pollutants and household ETS exposure. Communities in Taiwan were selected with the aim of maximizing the variability and minimizing the correlations of exposures to outdoor pollutants based on historic routine air monitoring data. In communities with pollution patterns of interest, neighborhoods with stable, largely middle-income populations were identified from 2004 census data. To address community-level sources of variability, we randomly sought participating communities within existing financial constraints. School district representatives in participating communities were consulted to identify suitable schools, based on demographic stability, likely parental cooperation, and absence of local pollution sources. Our study population finally comprised middleschool children from 14 diverse communities in Taiwan.

To permit cross-sectional assessment of environmental factors, we recruited 350-450 participants from each of the study communities. In each classroom targeted for participation, every student was invited to volunteer.
Classroom-level incentives were used to encourage participation. In each school, science, health, or physical education classes were targeted, excluding any special classes for gifted or learning-disabled subjects. The study protocol was approved by the Institutional Review Board at our university hospital, and it complied with the principles outlined in the Helsinki Declaration [28].

\section{Questionnaire of respiratory health}

A total of 5,804 seventh and eighth-grade children were recruited from public schools in 14 Taiwanese communities in 2007. The questionnaire was distributed in all communities simultaneously; subjects were given the forms by project staff following their pulmonary function tests and asked to complete and return them the following day. Questionnaire responses by parents or guardians were used to categorize children's asthma status, age at asthma diagnosis, wheeze, and history of bronchitic symptoms. Children were considered to have asthma if there was a positive answer to the question "Has a doctor ever diagnosed this child as having asthma?" Active asthma was defined as physician-diagnosed asthma with any asthma-related symptoms or illness in the previous 12 months. Serious asthma was defined as ever visit emergency rooms or ever hospitalized. Early-onset asthma was defined as age of onset for asthma before 5 years of age. Late-onset asthma was onset after 5 years of age. Wheeze was defined as any occurrence of the child's chest sounding wheezy or whistling. Current wheeze was defined as wheezing for 3 or more days out of the week for a month or longer in the previous year. Bronchitis status was positive if subjects had a physician-diagnosed episode in the prior 12 months. Chronic cough was defined as cough in the morning or at other times of the day that lasted for three months in a row or more during the prior 12 months. Chronic phlegm was defined by a "yes" answer to the question "Other than with colds, does this child usually seem congested in the chest or bring up phlegm?"

\section{Environmental tobacco smoke and other exposure}

We collected information about the current and past household smoking status of each participant's adult household members and regular household visitors. In utero exposure to ETS was defined as maternal smoking during pregnancy. Current number of household smokers, current number of cigarettes smoked inside the house per day, and years of household ETS exposure divided by age were recorded. Mutually exclusive categories of current household ETS exposure were defined as none, paternal smoke only, maternal smoke only, or both paternal and maternal smoke exposure. Personal smoking was defined as a history of smoking more than 100 cigarettes during subject's lifetime, as ascertained by a private interview during pulmonary function tests. 
In the baseline questionnaire, we also obtained information on children's sex, age, grade, parental education, number of siblings, gestational age, neonatal special care, personal/family history of atopy, and many residential risk factors, such as pet ownership, incense burning, air cleaner, air conditioner, dehumidifier, and carpet use at home. Occurrences of any severe chest illness, including pneumonia, croup, and other illnesses, before age 2 or after age 2 were dichotomized. Personal history of atopy included any history of hay fever, allergies to food or medicine, inhaled dusts, pollen, molds, animal fur or dander, or skin allergies. Parental history of atopy was defined as any biological parent in whom hay fever or allergies had been diagnosed. Parental history of asthma was defined as any biological parent in whom asthma had been diagnosed.

\section{Statistical analysis}

Unconditional logistic regression models were used to assess the individual and joint effects of ETS exposures on the occurrence of respiratory symptoms. On the basis of study design and a priori consideration of potential confounders, we included age, sex, parental education, parental history of asthma, parental history of atopy, and community in all models. If estimates of ETS effects changed by at least $10 \%$ when a covariate was included in the base models, then the covariate was included in the final models. The odds ratios (ORs) for the association of ETS exposures with early-onset and late-onset childhood asthma were computed using a likelihood method for polytomous logistic regression models. Subjects with missing covariate information were included in the model using missing indicators [29]. All analyses were conducted using SAS software version 9.1 (SAS Institute, Cary, NC, USA). Statistical significance was set at $\mathrm{p}<0.05$ based on two-sided estimation.

\section{Results}

The overall response rate in TCHS was $86.5 \%(2,432$ boys and 2,587 girls and their parents). The majority of participants were 12 years of age and from households with low parental educational levels (Table 1). All subjects were of Han Chinese ethnic origin. 3.1\% of children had a parental history of asthma and $25.0 \%$ had a parental history of atopy at the time of interview. 9.3\% of participants had no siblings. Premature birth occurred for $9.3 \%$ of children and $8.6 \%$ required neonatal special care (Table S1 in Additional file 1).

We excluded 37 subjects $(0.7 \%)$ with active smoking exposure in risk factor determination, due to sample size limitation for stratification analyses. In utero exposure to maternal smoking occurred in $3.9 \%$ of children, 49.0\% had exposure to household ETS at any time during their lives, and $44.9 \%$ had current household ETS exposure. The prevalence of paternal smoking was $36.0 \%$ and maternal smoking was $3.4 \%$ (Table 1 ). More than $15 \%$ of children had two or more smokers at home. In utero exposure to maternal smoking and household ETS exposure were highest among children with lower parental education level and among children from low-income families (Table S2 in Additional file 1).

The lifetime prevalence of wheeze was $11.6 \%$ and physician-diagnosed asthma was reported in $7.5 \%$ of children. In subjects with asthma, about two-thirds were diagnosed before 5 years of age, about one third of cases continued to require medication, and 59 cases $(1.3 \%)$ had experienced emergency room visits or hospitalization due to asthma attacks within the previous year (Table 2). The prevalence of respiratory symptoms was higher in children with in utero exposure or household ETS exposure than in unexposed children (Table S3 in Additional file 1).

To further investigate the different patterns of household ETS effects and in utero exposure to maternal smoking on children's respiratory health, we examined the relationships of these variables with subcategories of asthma, wheeze, and bronchitic symptoms (Table 3 and Table 4). After adjustment for potential confounders, we found that in utero exposure to maternal smoking was positively associated with all respiratory outcomes, with greater effects on serious asthma, such as emergency room visits or hospitalization within the previous year (OR, 4.33; 95\% CI, 2.03-9.24). Current household ETS exposure was significantly associated with increased prevalence of active asthma, ever wheeze, wheeze with nighttime awakening, and bronchitis. Maternal smoking was associated with increased prevalence of a wider range of wheeze subcategories, serious asthma, and chronic cough. Paternal smoking and past-only ETS exposure in the household were not associated with any respiratory outcome, but the presence of three or more household smokers was positively associated with all the subcategories of asthma, wheeze, and bronchitic symptoms. The number of current smokers at home showed significant trends in relationship to serious asthma, ever wheeze, wheeze with nighttime awakening, and chronic phlegm without cold (Table 3 and Table 4). In our cohort, the number of current household cigarettes smoked and the percent of ETS exposure during lifetime also showed increasing trends for risks of respiratory outcomes. When the patterns of ETS effects were stratified by the sex of the child, we found almost all respiratory outcomes showed different, but not statistically significant, effects between boys and girls (Table S4 in Additional file 1). In addition, we found little evidence that the magnitude of the effects of household ETS exposure on respiratory outcomes varied by age, 
Table 1 Demographic characteristics and environmental tobacco smoke (ETS) exposure of the study participants

\begin{tabular}{|c|c|c|c|c|c|c|}
\hline & & & & & & \\
\hline & & & & & & \\
\hline & $n$ & $\%$ & $n$ & $\%$ & $n$ & $\%$ \\
\hline Age, yr & & & & & & \\
\hline 12 & 3467 & 69.1 & 1696 & 69.7 & 1771 & 68.5 \\
\hline 13 & 1234 & 24.6 & 577 & 23.7 & 657 & 25.4 \\
\hline 14 & 318 & 6.3 & 159 & 6.5 & 159 & 6.1 \\
\hline Parental education, & & & & & & \\
\hline$\leqq 12$ & 3163 & 63.5 & 1509 & 62.7 & 1654 & 64.3 \\
\hline $13 \sim 15$ & 949 & 19.1 & 460 & 19.1 & 489 & 19.0 \\
\hline$\geqq 16$ & 867 & 17.4 & 437 & 18.2 & 430 & 16.7 \\
\hline Gestational age $†$ & & & & & & \\
\hline Full term & 4435 & 90.7 & 2113 & 89.6 & 2322 & 91.6 \\
\hline$<4$ wk early & 315 & 6.4 & 173 & 7.3 & 142 & 5.6 \\
\hline$\geqq 4$ wk early & 142 & 2.9 & 71 & 3.0 & 71 & 2.8 \\
\hline Family history of ast & & & & & & \\
\hline Yes & 140 & 3.1 & 68 & 3.1 & 72 & 3.1 \\
\hline Family history of atc & & & & & & \\
\hline Yes & 1257 & 25.0 & 641 & 25.0 & 643 & 25.0 \\
\hline Family income ${ }^{* *} \dagger$ & & & & & & \\
\hline$\leqq 400,000$ & 1750 & 37.7 & 792 & 35.4 & 958 & 39.8 \\
\hline $410,000 \sim 800,000$ & 1833 & 39.5 & 911 & 40.7 & 922 & 38.3 \\
\hline$\geqq 810,000$ & 1060 & 22.8 & 534 & 23.9 & 526 & 21.9 \\
\hline Active smoking & & & & & & \\
\hline Yes & 37 & 0.7 & 28 & 1.2 & 9 & 0.3 \\
\hline In utero exposuret & & & & & & \\
\hline Yes & 197 & 3.9 & 82 & 3.4 & 115 & 4.5 \\
\hline Lifetime ETSt & & & & & & \\
\hline Yes & 2445 & 49.0 & 1176 & 48.7 & 1269 & 49.4 \\
\hline Currently ETS† & & & & & & \\
\hline Yes & 2241 & 44.9 & 1078 & 44.6 & 1163 & 45.3 \\
\hline Previous ETS onlyt & & & & & & \\
\hline Yes & 204 & 4.1 & 98 & 4.1 & 106 & 4.1 \\
\hline Currently amount of & & & & & & \\
\hline 0 & 2778 & 55.8 & 1354 & 56.2 & 1424 & 55.4 \\
\hline$\leqq 10$ & 1728 & 34.7 & 838 & 34.8 & 890 & 34.6 \\
\hline$>10$ & 472 & 9.5 & 217 & 9.0 & 255 & 9.9 \\
\hline Percent of ETS****十 & & & & & & \\
\hline 0 & 2778 & 55.8 & 1354 & 56.3 & 1424 & 55.4 \\
\hline$\leqq 20 \%$ & 1406 & 28.3 & 693 & 28.8 & 713 & 27.7 \\
\hline$>20 \%$ & 791 & 15.9 & 358 & 14.9 & 433 & 16.8 \\
\hline Dad smokingt & & & & & & \\
\hline Yes & 1794 & 36.0 & 835 & 34.6 & 959 & 37.2 \\
\hline Mom smokingt & & & & & & \\
\hline Yes & 171 & 3.4 & 69 & 2.9 & 102 & 4.0 \\
\hline Number of smokers & & & & & & \\
\hline 0 & 2723 & 54.8 & 1368 & 56.8 & 1355 & 53.0 \\
\hline 1 & 1476 & 29.7 & 695 & 28.9 & 781 & 30.5 \\
\hline 2 & 513 & 10.3 & 238 & 9.9 & 275 & 10.8 \\
\hline$\geqq 3$ & 253 & 5.1 & 106 & 4.4 & 147 & 5.7 \\
\hline
\end{tabular}

*Atopy is defined as allergic rhinitis or atopic eczema.

**New Taiwan dollars per year ( $\$ 1$ US $=\$ 33$ New Taiwan).

***Average cigarettes per day

***Average percent of ETS in lifetime

† Number of subjects does not add up to total $\mathrm{N}$ because of missing data. 
Table 2 Prevalence of asthma, wheeze and bronchitic symptoms of the study participants

\begin{tabular}{lccccccc}
\hline & \multicolumn{2}{c}{ Total } & \multicolumn{2}{c}{ Boys } & \multicolumn{2}{c}{ Girls } \\
\cline { 2 - 8 } & $(\mathrm{n}=4982)$ & $(\mathrm{n}=2404)$ & $(\mathrm{n}=2578)$ \\
\cline { 2 - 8 } & $\mathrm{n}$ & $\%$ & $\mathrm{n}$ & $\%$ & $\mathrm{n}$ & $\%$ \\
\hline Asthma & & & & & & \\
$\quad$ Ever asthma & 369 & 7.5 & 195 & 8.2 & 174 & 6.8 \\
$\quad$ Active asthma & 167 & 3.4 & 89 & 3.7 & 78 & 3.0 \\
$\quad$ Early-onset asthma* & 237 & 4.9 & 123 & 5.3 & 114 & 4.6 \\
$\quad$ Late-onset asthma** & 120 & 2.6 & 64 & 2.8 & 56 & 2.3 \\
Treatments for asthma & & & & & & \\
$\quad$ Medication use & 122 & 2.5 & 65 & 2.7 & 57 & 2.2 \\
$\quad$ ER visit or hospitalization & 59 & 1.3 & 25 & 1.1 & 34 & 1.4 \\
Wheeze & & & & & & \\
$\quad$ Ever wheeze & 577 & 11.6 & 307 & 12.8 & 270 & 10.5 \\
$\quad$ Current wheeze & 181 & 3.7 & 88 & 3.7 & 93 & 3.7 \\
$\quad$ Awakened at night & 107 & 2.2 & 40 & 1.7 & 67 & 2.6 \\
Bronchitic symptoms & & & & & & \\
$\quad$ Brochitis & 286 & 5.8 & 160 & 6.7 & 126 & 4.9 \\
$\quad$ Chronic cough & 166 & 3.3 & 89 & 3.7 & 77 & 3.0 \\
$\quad$ Phlegm without cold & 214 & 4.3 & 111 & 4.7 & 103 & 4.0 \\
\hline
\end{tabular}

Number of subjects does not add up to total $\mathrm{N}$ because of missing data. *Early-onset: asthma diagnosed $\leqq 5 \mathrm{yr}$ of age.

**Late-onset: asthma diagnosed $>5 \mathrm{yr}$ of age. parental education, family income, or number of siblings (data not shown).

The risks of respiratory outcomes for maternal smoking alone were generally higher than for paternal smoking alone (Table 5). The effect of maternal smoking and paternal smoking exposure did not vary substantially between boys and girls. Although maternal smoking alone and paternal smoking alone were not independently associated with respiratory outcomes, joint exposure appeared to increase the individual effects of parental ETS on serious asthma (OR, 4.30; 95\% CI, 1.57-11.80), ever wheeze (OR, 1.81; 95\% CI, 1.09-3.00), current wheeze (OR, 2.74; 95\% CI, 1.42-5.29), bronchitis (OR, 1.97; 95\% CI, 1.03-3.77), and chronic phlegm without cold (OR, 2.65; 95\% CI, 1.39-5.03).

After adjustment for potential confounders, in utero exposure to maternal smoking had an OR of 1.67 (95\% CI, 0.93-2.99) with asthma diagnosed before 5 years of age and an OR of 1.49 (95\% CI 0.69-3.19) with asthma diagnosed after 5 years of age (Table 6). In our population, paternal or maternal smoking alone did not show effects, but joint exposure to parental smoking showed significant effect on early-onset asthma (OR, 2.01; 95\%

Table 3 Effects of environmental tobacco smoke exposure (ETS) on subcategories of asthma

\begin{tabular}{|c|c|c|c|c|c|c|c|c|}
\hline & \multicolumn{4}{|c|}{ Asthma } & \multicolumn{4}{|c|}{ Treatments for asthma } \\
\hline & \multicolumn{2}{|c|}{ Ever asthma } & \multicolumn{2}{|c|}{ Active asthma } & \multicolumn{2}{|c|}{ Medication use } & \multicolumn{2}{|c|}{ ER visit or hospitalization } \\
\hline & OR & $95 \% \mathrm{Cl}$ & OR & $95 \% \mathrm{Cl}$ & OR & $95 \% \mathrm{Cl}$ & OR & $95 \% \mathrm{Cl}$ \\
\hline \multicolumn{9}{|l|}{ ETS } \\
\hline In utero exposure & 1.53 & $(0.95,2.48)$ & 2.06 & $(1.14,3.70)$ & 1.95 & $(0.99,3.83)$ & 4.33 & $(2.03,9.24)$ \\
\hline Currently & 1.15 & $(0.92,1.44)$ & 1.39 & $(1.00,1.93)$ & 1.33 & $(0.91,1.95)$ & 1.71 & $(0.98,2.96)$ \\
\hline Previous only & 0.79 & $(0.43,1.44)$ & 0.69 & $(0.28,1.72)$ & 0.56 & $(0.17,1.79)$ & NA & \\
\hline \multicolumn{9}{|l|}{ ETS sources } \\
\hline Dad & 1.07 & $(0.85,1.35)$ & 1.11 & $(0.79,1.55)$ & 0.99 & $(0.67,1.47)$ & 1.28 & $(0.74,2.20)$ \\
\hline Mom & 1.40 & $(0.82,2.39)$ & 1.67 & $(0.84,3.31)$ & 0.99 & $(0.39,2.52)$ & 3.16 & $(1.29,7.77)$ \\
\hline \multicolumn{9}{|l|}{ Number of smokers } \\
\hline 0 & 1 & & 1 & & 1 & & 1 & \\
\hline 1 & 0.91 & $(0.71,1.19)$ & 1.05 & $(0.72,1.52)$ & 1.01 & $(0.66,1.57)$ & 1.04 & $(0.54,2.01)$ \\
\hline 2 & 0.80 & $(0.53,1.21)$ & 0.92 & $(0.51,1.67)$ & 0.76 & $(0.37,1.56)$ & 0.58 & $(0.17,1.95)$ \\
\hline$\geqq 3$ & 1.61 & $(1.04,2.50)$ & 2.28 & $(1.30,4.01)$ & 2.56 & $(1.40,4.69)$ & 4.56 & $(2.20,9.46)$ \\
\hline$p$ value for trend & 0.47 & & 0.05 & & 0.07 & & 0.004 & \\
\hline \multicolumn{9}{|c|}{ Currently amount of ETS* } \\
\hline 0 & 1 & & 1 & & 1 & & 1 & \\
\hline$\leqq 10$ & 1.06 & $(0.83,1.36)$ & 1.26 & $(0.88,1.80)$ & 1.14 & $(0.75,1.74)$ & 1.21 & $(0.65,2.26)$ \\
\hline$>10$ & 1.42 & $(0.99,2.03)$ & 2.02 & $(1.27,3.24)$ & 2.21 & $(1.32,3.71)$ & 2.81 & $(1.38,5.73)$ \\
\hline$p$ value for trend & 0.10 & & 0.005 & & 0.009 & & 0.01 & \\
\hline \multicolumn{9}{|l|}{ Percent of ETS** } \\
\hline 0 & 1 & & 1 & & 1 & & 1 & \\
\hline$\leqq 20 \%$ & 0.99 & $(0.76,1.29)$ & 1.13 & $(0.77,1.67)$ & 1.19 & $(0.77,1.85)$ & 1.12 & $(0.57,2.18)$ \\
\hline$>20 \%$ & 1.43 & $(1.07,1.92)$ & 1.79 & $(1.19,2.69)$ & 1.52 & $(0.93,2.46)$ & 2.50 & $(1.32,4.74)$ \\
\hline$p$ value for trend & 0.04 & & 0.01 & & 0.09 & & 0.01 & \\
\hline
\end{tabular}

Models are adjusted for age, sex, parental education, family history of asthma, family history of atopy, gestational age, and community.

*Average cigarettes per day

**Average percent of ETS in lifetime 
Table 4 Effects of environmental tobacco smoke exposure (ETS) on subcategories of wheeze and bronchitic symptoms

\begin{tabular}{|c|c|c|c|c|c|c|c|c|c|c|c|c|}
\hline & \multicolumn{6}{|c|}{ Wheeze } & \multicolumn{6}{|c|}{ Bronchitic symptoms } \\
\hline & \multicolumn{2}{|c|}{ Ever wheeze } & \multicolumn{2}{|c|}{ Current wheeze } & \multicolumn{2}{|c|}{ Awakened at night } & \multicolumn{2}{|c|}{ Brochitis } & \multicolumn{2}{|c|}{ Chronic cough } & \multicolumn{2}{|c|}{$\begin{array}{l}\text { Phlegm without } \\
\text { cold }\end{array}$} \\
\hline & OR & $95 \% \mathrm{Cl}$ & OR & $95 \% \mathrm{Cl}$ & OR & $95 \% \mathrm{Cl}$ & OR & $95 \% \mathrm{Cl}$ & OR & $95 \% \mathrm{Cl}$ & OR & $95 \% \mathrm{Cl}$ \\
\hline \multicolumn{13}{|l|}{$\overline{\text { ETS }}$} \\
\hline In utero exposure & 1.98 & $(1.35,2.89)$ & 3.21 & $(1.95,5.29)$ & 3.18 & $(1.70,5.96)$ & 1.88 & $(1.11,3.17)$ & 1.99 & $(1.10,3.60)$ & 2.04 & $(1.21,3.46)$ \\
\hline Currently & 1.28 & $(1.07,1.54)$ & 1.30 & $(0.96,1.78)$ & 1.64 & $(1.09,2.46)$ & 1.39 & $(1.08,1.79)$ & 1.13 & $(0.82,1.57)$ & 0.97 & $(0.73,1.30)$ \\
\hline Previous only & 1.08 & $(0.69,1.69)$ & 1.36 & $(0.70,2.65)$ & 0.21 & $(0.03,1.51)$ & 1.43 & $(0.82,2.49)$ & 1.56 & $(0.80,3.04)$ & 1.57 & $(0.87,2.82)$ \\
\hline \multicolumn{13}{|l|}{ ETS sources } \\
\hline Dad & 1.09 & $(0.90,1.32)$ & 0.95 & $(0.69,1.32)$ & 1.39 & $(0.93,2.08)$ & 1.01 & $(0.77,1.31)$ & 0.95 & $(0.68,1.33)$ & 1.21 & $(0.91,1.62)$ \\
\hline Mom & 1.76 & $(1.15,2.68)$ & 2.7 & $(1.54,4.75)$ & 2.17 & $(1.02,4.64)$ & 1.68 & $(0.94,3.03)$ & 2.39 & $(1.30,4.39)$ & 1.77 & $(0.97,3.22)$ \\
\hline \multicolumn{13}{|l|}{ Number of smokers } \\
\hline 0 & 1 & & 1 & & 1 & & 1 & & 1 & & 1 & \\
\hline 1 & 0.98 & $(0.79,1.22)$ & 0.96 & $(0.66,1.38)$ & 1.39 & $(0.87,2.22)$ & 0.96 & $(0.71,1.28)$ & 0.78 & $(0.53,1.16)$ & 1.02 & $(0.73,1.42)$ \\
\hline 2 & 1.45 & $(1.09,1.94)$ & 1.53 & $(0.96,2.42)$ & 1.83 & $(0.99,3.37)$ & 1.33 & $(0.89,1.98)$ & 1.00 & $(0.58,1.72)$ & 1.13 & $(0.71,1.81)$ \\
\hline$\geqq 3$ & 1.63 & $(1.12,2.37)$ & 1.43 & $(0.77,2.66)$ & 3.51 & $(1.87,6.61)$ & 1.6 & $(0.95,2.69)$ & 1.93 & $(1.09,3.42)$ & 2.48 & $(1.52,4.03)$ \\
\hline$p$ value for trend & 0.003 & & 0.10 & & $<0.001$ & & 0.07 & & 0.20 & & 0.005 & \\
\hline \multicolumn{13}{|l|}{$\begin{array}{l}\text { Currently amount of } \\
\text { ETS* }\end{array}$} \\
\hline 0 & 1 & & 1 & & 1 & & 1 & & 1 & & 1 & \\
\hline$\leqq 10$ & 1.20 & $(0.98,1.46)$ & 1.30 & $(0.93,1.82)$ & 1.40 & $(0.90,2.17)$ & 1.33 & $(1.01,1.74)$ & 0.89 & $(0.61,1.28)$ & 0.90 & $(0.66,1.23)$ \\
\hline$>10$ & 1.64 & $(1.23,2.19)$ & 1.43 & $(0.88,2.34)$ & 2.38 & $(1.36,4.18)$ & 1.50 & $(0.99,2.27)$ & 2.20 & $(1.42,3.42)$ & 1.29 & $(0.83,1.99)$ \\
\hline$p$ value for trend & 0.001 & & 0.07 & & 0.003 & & 0.02 & & 0.01 & & 0.58 & \\
\hline \multicolumn{13}{|l|}{ Percent of ETS } \\
\hline 0 & 1 & & 1 & & 1 & & 1 & & 1 & & 1 & \\
\hline$\leqq 20 \%$ & 1.15 & $(0.93,1.42)$ & 0.95 & $(0.64,1.40)$ & 1.14 & $(0.70,1.87)$ & 1.24 & $(0.92,1.66)$ & 0.64 & $(0.42,0.99)$ & 0.79 & $(0.56,1.12)$ \\
\hline$>20 \%$ & 1.56 & $(1.22,1.98)$ & 2.06 & $(1.43,2.99)$ & 2.40 & $(1.49,3.85)$ & 1.66 & $(1.19,2.31)$ & 2.13 & $(1.47,3.08)$ & 1.29 & $(0.89,1.85)$ \\
\hline$p$ value for trend & 0.001 & & 0.001 & & 0.001 & & 0.003 & & 0.001 & & 0.41 & \\
\hline
\end{tabular}

Models are adjusted for age, sex, parental education, family history of asthma, family history of atopy, gestational age, and community.

*Average cigarettes per day

**Average percent of ETS in lifetime

CI, 1.00-4.02). However, joint exposure to parental smoking did not show a significant effect on late-onset asthma (OR, 1.17; 95\% CI, 0.36-3.87). Although estimates were imprecise, the effects of current exposure to maternal smoking appeared to be larger in the younger age at diagnosis' group. Children with three or more household smokers had a significant risk for early-onset asthma (OR, 2.80; 95\% CI, 1.27-6.17).

\section{Discussion}

Our population-based epidemiologic study showed the harmful effects of fetal and current exposure to tobacco smoke products. Prenatal exposure due to maternal smoking had the strongest effects on respiratory symptoms. Current household ETS exposure also showed significant adverse effects, but past-only ETS exposure was not associated with any respiratory outcome. In addition, the number of current household cigarettes smoked, the percentage of ETS exposure during lifetime, and the number of current smokers at home showed increasing trends in risks of respiratory symptoms.
Age, sex, active smoking habits, parental atopic history, and parental education might contribute to asthma and wheeze in childhood $[3,30]$. We minimized interference from these confounders by recruiting lifelong nonsmokers of similar age at study entry, and adjusting potential confounders by regression models. Although maternal smoking was, as expected, a strong determinant of preterm delivery and low birth weight, and these adverse pregnancy outcomes were strong predictors of respiratory problems, only gestational age showed an effect in our study. Adjustment for indoor residential factors resulted in only small changes in the effect estimates, and these covariates were not included in the final models.

In our population, 197 (3.9\%) children were reported to have had in utero ETS exposure (Table 1). The prevalence is much lower than other Western studies $[11,19,25,27,31-34]$. In utero exposure to maternal smoking showed significant adverse effects on respiratory health, with an adjusted OR of 3.21 (95\% CI 1.955.29) for current wheeze. In contrast, current exposure 
Table 5 Joint effects of parental smoking on subcategories of asthma, wheeze and bronchitic symptoms

\begin{tabular}{|c|c|c|c|c|c|c|c|}
\hline & \multicolumn{7}{|c|}{ Parental smoking } \\
\hline & \multirow[t]{2}{*}{ None } & \multicolumn{2}{|c|}{ Dad only } & \multicolumn{2}{|c|}{ Mom only } & \multicolumn{2}{|c|}{ Both } \\
\hline & & OR & $95 \% \mathrm{Cl}$ & OR & $95 \% \mathrm{Cl}$ & OR & $95 \% \mathrm{Cl}$ \\
\hline \multicolumn{8}{|l|}{ Asthma } \\
\hline Ever asthma & 1 & 1.03 & $(0.81,1.32)$ & 1.05 & $(0.36,3.03)$ & 1.60 & $(0.86,2.96)$ \\
\hline Active asthma & 1 & 1.08 & $(0.76,1.52)$ & 1.62 & $(0.47,5.50)$ & 1.76 & $(0.77,4.01)$ \\
\hline \multicolumn{8}{|l|}{ Treatments for asthma } \\
\hline Medication use & 1 & 1.01 & $(0.68,1.51)$ & 1.33 & $(0.30,5.80)$ & 0.85 & $(0.25,2.82)$ \\
\hline ER visit or hospitalization & 1 & 1.09 & $(0.60,1.96)$ & 1.45 & $(0.18,11.50)$ & 4.30 & $(1.57,11.80)$ \\
\hline \multicolumn{8}{|l|}{ Wheeze } \\
\hline Ever wheeze & 1 & 1.06 & $(0.87,1.29)$ & 1.77 & $(0.83,3.78)$ & 1.81 & $(1.09,3.00)$ \\
\hline Current wheeze & 1 & 0.85 & $(0.60,1.20)$ & 2.11 & $(0.72,6.18)$ & 2.74 & $(1.42,5.29)$ \\
\hline Awakened at night & 1 & 1.39 & $(0.91,2.11)$ & 3.10 & $(0.90,10.70)$ & 2.23 & $(0.85,5.82)$ \\
\hline \multicolumn{8}{|l|}{ Bronchitic symptoms } \\
\hline Brochitis & 1 & 0.94 & $(0.72,1.24)$ & 0.83 & $(0.20,3.55)$ & 1.97 & $(1.03,3.77)$ \\
\hline Chronic cough & 1 & 0.97 & $(0.69,1.38)$ & 4.38 & $(1.84,10.40)$ & 1.55 & $(0.65,3.68)$ \\
\hline Phlegm without cold & 1 & 1.10 & $(0.81,1.49)$ & 0.37 & $(0.05,2.77)$ & 2.65 & $(1.39,5.03)$ \\
\hline
\end{tabular}

*Models are adjusted for age, sex, parental education, family history of asthma, family history of atopy, gestational age, and community.

to ETS showed a smaller effect, with an adjusted OR of 1.30 (95\% CI 0.96-1.78) for current wheeze (Table 3 and Table 4). Our findings on the stronger effect of prenatal exposure compared with current ETS exposure are consistent with the results in the 24 Cities Study [25]. Other studies of Californian[11] and Russian[32] children also provided evidence of the relative importance of prenatal exposure on respiratory outcomes.

These associations of in utero exposure with respiratory outcomes are consistent with the evidence that in utero exposure adversely affects postnatal pulmonary function and increases the occurrence of respiratory symptoms [19,27,31-34]. Furthermore, in utero exposure may also affect the development and maturation of the pulmonary immune system [35]. Inappropriate persistence of a $\mathrm{Th}_{2}$-dominant response appears to increase allergic sensitization upon sufficient exposure to a variety of common antigens that underlie the pathogenesis of asthma [36]. Our result is in agreement with the biological plausibility that in utero exposure to maternal smoking, through mechanisms of decreasing pulmonary function and increasing bronchial hyper-responsiveness (BHR), induces asthma occurrence, especially during the first five years of life (Table 6).

Exposure at home by parental smoking is likely the most common source of ETS exposure in children. Exposure to household ETS among children has been reported to vary from $27.6 \%$ to $77.8 \%$ [8]. Our prevalence of $49.0 \%$ for lifetime ETS exposure and $44.9 \%$ for current ETS exposure are similar to many Western countries, but are far lower than the prevalence of $80.0 \%$ reported in a recent study in a Chinese population [22]. While a review of epidemiologic studies on allergies has been inconclusive [16-22], murine model and human experimental studies may explain the findings of the present investigation. In our results, current household cigarettes smoked, percent of ETS exposure during lifetime, and the number of current smokers at home all showed increasing trends in the risks of respiratory outcomes, consistent with the dose-response relationship of household ETS in many recent studies $[34,37,38]$. In a recent meta-analysis of the effects of household ETS on asthma and wheeze, Vork et al reported a summary relative risk for asthma of 1.21 (95\% CI 1.17-1.26) that is consistent with our estimate of 1.15 (95\% CI 0.92-1.44). Our estimate for the association between household ETS and active asthma (1.39, 95\% CI 1.00-1.93) is slightly higher than that from the meta-analysis $(1.25,95 \%$ CI $1.21-1.30)$, but the confidence intervals show considerable overlap [39]. The literature on the relationship between household ETS exposure and respiratory symptoms gives conflicting results with regard to sex differences in susceptibility [40]. We found almost all respiratory outcomes showed non-significant interaction between household ETS exposure and sex in health outcomes (Table S4 in Additional file 1), consistent with the findings from a recent study in Singapore [38].

The prevalence of maternal and paternal smoking in this study was $3.4 \%$ and $36.0 \%$, respectively, which is comparable to an earlier survey in Singapore [41]. The prevalence of maternal smoking in Taiwan is much lower than the $13 \%$ reported in Sweden [42], 23.8\% in USA [43], and 32\% in Austria [44]. Studies using cotinine as a biomarker show that the strength of the 
Table 6 Effects of household environmental tobacco smoke (ETS) exposure on asthma, stratified by age at asthma diagnosis

\begin{tabular}{|c|c|c|c|c|}
\hline & & $\begin{array}{l}\text { I-onset } \\
\text { hmat }\end{array}$ & & $\begin{array}{l}\text {-onset } \\
\text { hmał }\end{array}$ \\
\hline & OR & $95 \% \mathrm{Cl}$ & OR & $95 \% \mathrm{Cl}$ \\
\hline ETS & & & & \\
\hline In utero exposure & 1.67 & $(0.93,2.99)$ & 1.49 & $(0.69,3.19)$ \\
\hline Currently & 1.15 & $(0.87,1.52)$ & 1.07 & $(0.74,1.57)$ \\
\hline Previous only & 0.70 & $(0.32,1.53)$ & 0.85 & $(0.31,2.35)$ \\
\hline ETS sources & & & & \\
\hline Dad & 1.05 & $(0.79,1.41)$ & 1.13 & $(0.77,1.66)$ \\
\hline Mom & 1.60 & $(0.85,2.99)$ & 0.92 & $(0.33,2.58)$ \\
\hline Number of smokers & & & & \\
\hline 0 & 1 & & 1 & \\
\hline 1 & 0.72 & $(0.42,1.24)$ & 0.74 & $(0.38,1.46)$ \\
\hline 2 & 0.49 & $(0.22,1.10)$ & 0.86 & $(0.34,2.17)$ \\
\hline$\geqq 3$ & 2.80 & $(1.27,6.17)$ & 2.07 & $(0.73,5.88)$ \\
\hline$p$ value for trend & 0.75 & & 0.31 & \\
\hline Currently amount of & & & & \\
\hline 0 & 1 & & 1 & \\
\hline$\leqq 10$ & 0.86 & $(0.56,1.32)$ & 0.82 & $(0.46,1.44)$ \\
\hline$>10$ & 1.51 & $(0.85,2.66)$ & 1.53 & $(0.73,3.21)$ \\
\hline$p$ value for trend & 0.20 & & 0.39 & \\
\hline Percent of ETS** & & & & \\
\hline 0 & 1 & & 1 & \\
\hline$\leqq 20 \%$ & 0.77 & $(0.50,1.18)$ & 0.86 & $(0.49,1.52)$ \\
\hline$>20 \%$ & 1.61 & $(1.02,2.56)$ & 1.34 & $(0.71,2.51)$ \\
\hline $\begin{array}{l}p \text { value for trend } \\
\text { parental smoking }\end{array}$ & 0.11 & & 0.46 & \\
\hline none & 1 & & 1 & \\
\hline dad only & 1.00 & $(0.74,1.36)$ & 1.16 & $(0.78,1.72)$ \\
\hline mom only & 0.88 & $(0.21,3.78)$ & 0.71 & $(0.09,5.34)$ \\
\hline both & 2.01 & $(1.00,4.02)$ & 1.17 & $(0.36,3.87)$ \\
\hline
\end{tabular}

Models are adjusted for age, sex, parental education, parental history of asthma, parental history of atopy, gestational age, and community.

† Early-onset: asthma diagnosed $\leqq 5 \mathrm{yr}$ of age.

₹ Late-onset: asthma diagnosed $>5 \mathrm{yr}$ of age.

*Average cigarettes per day

** Percent of ETS exposure in lifetime

association between maternal smoking and respiratory outcomes is in part due to larger ETS doses from maternal smoking than from other sources [24]. In our study, maternal ETS conferred a higher risk of respiratory symptoms compared with paternal ETS (Table 3 and Table 4). Several reasons could explain this phenomenon: mothers have more direct contact with their children at home compared with fathers; women who smoke during pregnancy are likely to continue smoking after delivery. In Taiwan, the ratio of current smoker/ ex-smoker rates in adulthood is close to 7 [15], far higher than the ratio near to one in the United States [45] and indicating a particularly low rate of smoking cessation in Taiwanese adults. Depending on which symptom is considered, our results show the higher risk for ETS from both parents when compared with just maternal or just paternal ETS exposure (Table 5). The reasons for this are not clear and could be partly attributed to the behavior of the parents [23].

We found that in utero exposure to maternal smoking had larger effects on early-onset asthma than those asthmatics diagnosed after 5 years of age (Table 6). Previous studies showed a stronger risk for incident asthma or wheezing illness among younger children compared with older children [21,31]. These investigators suggested that the stronger relationship might be attributed to exacerbation of intercurrent infection among young children, resulting in transient wheeze that would tend to diminish with age and increasing airway caliber. The proposed mechanism would suggest that household ETS may not be the sole primary cause of early childhood asthma.

Our study has some limitations. Because of crosssectional data, the factors we studied may have affected outcome prevalence through effects on disease duration rather than disease incidence. Biases could also be introduced if parents or children change their timeactivity patterns to avoid ETS exposure. However, we note that the prevalence of past-only ETS exposure is very low, suggesting that adult smoking patterns would not differentially change over time. Differential participation by children with respiratory outcomes who had different ETS exposure histories is unlikely to have been significant enough to produce substantial bias, as participation rates in each classroom were high. Retrospective recall of tobacco smoking by questionnaire is likely to have produced some misclassification of exposure. However, the validity of ETS exposure estimates based on questionnaire responses have been investigated and found to provide reasonably valid data [46-49]. It can be expected that more parents would not want to be seen as flouting the law and thus report that they are smoking within the privacy of their homes. Under these conditions, it can be anticipated that the proportions of exposure misclassification are likely to be non-differential for symptomatic children as for the healthy children.

In summary, our results showed that prenatal and current household ETS exposure in Taiwan had significant adverse effects on respiratory health in children. Eliminating household ETS exposure may offer the most promising opportunity for reducing morbidity, because this risk factor is potentially modifiable. Public health policy for reducing the burden of respiratory symptoms may require a stronger focus on smoking cessation in the home, where children could gain significant health benefits. 
Additional file 1: Table S1. Characteristics of the study participants in TCHS by sex. Table S2. Demographic characteristics for the percentage of household environmental tobacco smoke (ETS) exposure categories in TCHS. Table S3. Percentage of participants in TCHS with asthma, wheeze and bronchitic symptoms within household environmental tobacco smoke (ETS) exposure categories. Table S4. Effects of household environmental tobacco smoke (ETS) exposure on subcategories of asthma, wheeze and bronchitic symptoms, stratified by sex. Click here for file

[http://www.biomedcentral.com/content/supplementary/1465-9921-1111-S1.DOC]

\section{Acknowledgements}

This study was supported by grant \#95-2314-B-006-103 and \#96-2314-B-006053 from National Science Council. The authors thank the field workers, teachers, and other school staff who supported data collection, and all the parents and children who participated in this study.

\section{Author details}

'Institute of Preventive Medicine, College of Public Health, National Taiwan University, Taipei, Taiwan. ${ }^{2}$ Institute of Health Policy and Management, College of Public Health, National Taiwan University, Taipei, Taiwan. ${ }^{3}$ Department of Occupational Safety and Health, College of Public Health, China Medical University, Taichung, Taiwan. ${ }^{4}$ Research Center for Genes, Environment and Human Health, College of Public Health, National Taiwan University, Taipei, Taiwan.

\section{Authors' contributions}

$\mathrm{CHT}$ analyzed data and drafted this paper. $\mathrm{JHH}$ was involved in the study design and field work. BFH was involved with statistical conception and critical revision of the manuscript. YLL was the coordinator of TCHS, who worked on content development, statistical analysis, obtaining funding, and supervision of the study.

\section{Competing interests}

The authors declare that they have no competing interests.

\section{Received: 15 October 2009}

Accepted: 29 January 2010 Published: 29 January 2010

\section{References}

1. Heinrich J, Hoelscher B, Frye C, Meyer I, Wjst M, Wichmann HE: Trends in prevalence of atopic diseases and allergic sensitization in children in Eastern Germany. Eur Respir J 2002, 19:1040-1046.

2. Hong SJ, Lee MS, Sohn MH, Shim JY, Han YS, Park KS, Ahn YM, Son BK, Lee HB: Self-reported prevalence and risk factors of asthma among Korean adolescents: 5-year follow-up study, 1995-2000. Clin Exp Allergy 2004, 34:1556-1562.

3. Lee $Y L$, Lin $Y C$, Hwang BF, Guo YL: Changing prevalence of asthma in Taiwanese adolescents: two surveys 6 years apart. Pediatr Allergy Immunol 2005, 16:157-164.

4. Maziak W, Behrens T, Brasky TM, Duhme H, Rzehak P, Weiland SK, Keil U: Are asthma and allergies in children and adolescents increasing? Results from ISAAC phase I and phase III surveys in Munster, Germany. Allergy 2003, 58:572-579.

5. Hopkin JM: Genetics of atopy. Pediatr Allergy Immunol 1995, 6:139-144.

6. Palmer L, Valinsky IJ, Pikora T, Zubrick SR, Landau LI: Environmental factors and asthma and allergy in schoolchildren from Western Australia. Eur Respir J 1999, 14:1351-1357.

7. Brower V: World Health Organization focuses on antitobacco efforts in developing nations through treaty. Journal of the National Cancer Institute 2006, 98:667-668.

8. Warren CW, Jones NR, Peruga A, Chauvin J, Baptiste JP, Costa de Silva V, el Awa F, Tsouros A, Rahman K, Fishburn B, Bettcher DW, Asma S: Global youth tobacco surveillance, 2000-2007. MMWR Surveill Summ 2008, 57:1-28
9. Cook DG, Strachan DP: Health effects of passive smoking. 3. Parental smoking and prevalence of respiratory symptoms and asthma in school age children. Thorax 1997, 52:1081-1094.

10. Gilliland FD, Berhane K, Islam T, Wenten M, Rappaport E, Avol E, Gauderman WJ, McConnell R, Peters JM: Environmental tobacco smoke and absenteeism related to respiratory illness in schoolchildren. American journal of epidemiology 2003, 157:861-869.

11. Gilliland FD, Li YF, Peters JM: Effects of maternal smoking during pregnancy and environmental tobacco smoke on asthma and wheezing in children. American journal of respiratory and critical care medicine 2001, 163:429-436.

12. Martinez FD, Cline M, Burrows B: Increased incidence of asthma in children of smoking mothers. Pediatrics 1992, 89:21-26.

13. Rushton L, Courage C, Green E: Estimation of the impact on children's health of environmental tobacco smoke in England and Wales. The journal of the Royal Society for the Promotion of Health 2003, 123:175-180.

14. Beasley R, Crane J, Lai CK, Pearce N: Prevalence and etiology of asthma. J Allergy Clin Immunol 2000, 105:S466-472.

15. Wen CP, Levy DT, Cheng TY, Hsu CC, Tsai SP: Smoking behaviour in Taiwan, 2001. Tobacco control 2005, 14(Suppl 1):i51-55.

16. Biagini JM, LeMasters GK, Ryan PH, Levin L, Reponen T, Bernstein DI, Villareal M, Khurana Hershey GK, Burkle J, Lockey J: Environmental risk factors of rhinitis in early infancy. Pediatr Allergy Immunol 2006, 17:278-284.

17. Kurosaka F, Nakatani Y, Terada T, Tanaka A, Ikeuchi H, Hayakawa A, Konohana A, Oota K, Nishio H: Current cat ownership may be associated with the lower prevalence of atopic dermatitis, allergic rhinitis, and Japanese cedar pollinosis in schoolchildren in Himeji, Japan. Pediatr Allergy Immunol 2006, 17:22-28.

18. Raherison C, Penard-Morand C, Moreau D, Caillaud D, Charpin D, Kopfersmitt C, Lavaud F, Taytard A, Annesi-maesano I: In utero and childhood exposure to parental tobacco smoke, and allergies in schoolchildren. Respiratory medicine 2007, 101:107-117.

19. Spengler JD, Jaakkola JJ, Parise H, Katsnelson BA, Privalova LI, Kosheleva AA: Housing characteristics and children's respiratory health in the Russian Federation. American journal of public health 2004, 94:657-662.

20. Stazi MA, Sampogna F, Montagano G, Grandolfo ME, Couilliot MF, AnnesiMaesano I: Early life factors related to clinical manifestations of atopic disease but not to skin-prick test positivity in young children. Pediatr Allergy Immunol 2002, 13:105-112.

21. Strachan DP, Cook DG: Health effects of passive smoking .5. Parental smoking and allergic sensitisation in children. Thorax 1998, 53:117-123.

22. Zhao Z, Zhang Z, Wang Z, Ferm M, Liang Y, Norback D: Asthmatic symptoms among pupils in relation to winter indoor and outdoor air pollution in schools in Taiyuan, China. Environmental health perspectives 2008, 116:90-97.

23. Johansson A, Halling A, Hermansson G, Ludvigsson J: Assessment of smoking behaviors in the home and their influence on children's passive smoking: development of a questionnaire. Annals of epidemiology 2005, 15:453-459.

24. Jarvis $D$, Burney $P$ : $A B C$ of allergies. The epidemiology of allergic disease. BMJ 1998, 316:607-610

25. Cunningham J, O'Connor GT, Dockery DW, Speizer FE: Environmental tobacco smoke, wheezing, and asthma in children in 24 communities. American journal of respiratory and critical care medicine 1996, 153:218-224.

26. Jaakkola JJ, Gissler M: Maternal smoking in pregnancy, fetal development, and childhood asthma. American journal of public health 2004, 94:136-140.

27. Jaakkola JJ, Jaakkola MS: Effects of environmental tobacco smoke on the respiratory health of children. Scandinavian journal of work, environment \& health 2002, 28(Suppl 2):71-83.

28. Hopper JL, Jenkins MA, Carlin JB, Giles GG: Increase in the self-reported prevalence of asthma and hay fever in adults over the last generation: a matched parent-offspring study. Aust J Public Health 1995, 19:120-124.

29. Huberman M, Langholz B: Application of the missing-indicator method in matched case-control studies with incomplete data. American journal of epidemiology 1999, 150:1340-1345

30. Lee $Y L$, Lin $Y C$, Hsiue TR, Hwang BF, Guo YL: Indoor and outdoor environmental exposures, parental atopy, and physician-diagnosed asthma in Taiwanese schoolchildren. Pediatrics 2003, 112:e389. 
31. Cook DG, Strachan DP: Health effects of passive smoking-10: Summary of effects of parental smoking on the respiratory health of children and implications for research. Thorax 1999, 54:357-366.

32. Jaakkola JJ, Kosheleva AA, Katsnelson BA, Kuzmin SV, Privalova LI, Spengler JD: Prenatal and postnatal tobacco smoke exposure and respiratory health in Russian children. Respiratory research 2006, 7:48.

33. Zacharasiewicz A, Zidek T, Haidinger G, Waldhor T, Vutuc C, Zacharasiewicz A, Goetz M, Pearce N: Symptoms suggestive of atopic rhinitis in children aged 6-9 years and the indoor environment. Allergy 2000, 55:945-950.

34. Zlotkowska R, Zejda JE: Fetal and postnatal exposure to tobacco smoke and respiratory health in children. European journal of epidemiology 2005 20:719-727.

35. Tager IB: Smoking and childhood asthma-where do we stand?. American journal of respiratory and critical care medicine 1998, 158:349-351.

36. Holt PG, Macaubas C, Stumbles PA, Sly PD: The role of allergy in the development of asthma. Nature 1999, 402:B12-17.

37. Keskinoglu P, Cimrin D, Aksakoglu G: The impact of passive smoking on the development of lower respiratory tract infections in children. Journal of tropical pediatrics 2007, 53:319-324.

38. Zuraimi MS, Tham KW, Chew FT, Ooi PL, David K: Home exposures to environmental tobacco smoke and allergic symptoms among young children in Singapore. International archives of allergy and immunology 2008, 146:57-65.

39. Vork $\mathrm{KL}$, Broadwin RL, Blaisdell RJ: Developing asthma in childhood from exposure to secondhand tobacco smoke: insights from a metaregression. Environmental health perspectives 2007, 115:1394-1400.

40. Cook DG, Strachan DP: Parental smoking, bronchial reactivity and peak flow variability in children. Thorax 1998, 53:295-301.

41. Stoddard JJ, Miller T: Impact of parental smoking on the prevalence of wheezing respiratory illness in children. Am J Epidemiol 1995, 141:96-102.

42. Cnattingius S: The epidemiology of smoking during pregnancy: smoking prevalence, maternal characteristics, and pregnancy outcomes. Nicotine Tob Res 2004, 6(Suppl 2):S125-140.

43. Gergen PJ, Fowler JA, Maurer KR, Davis WW, Overpeck MD: The burden of environmental tobacco smoke exposure on the respiratory health of children 2 months through 5 years of age in the United States: Third National Health and Nutrition Examination Survey, 1988 to 1994. Pediatrics 1998, 101:E8.

44. Al Mamun A, O'Callaghan FV, Alati R, O'Callaghan M, Najman JM, Williams GM, Bor W: Does maternal smoking during pregnancy predict the smoking patterns of young adult offspring? A birth cohort study. Tobacco control 2006, 15:452-457.

45. Strachan DP, Cook DG: Health effects of passive smoking. 6. Parental smoking and childhood asthma: longitudinal and case-control studies. Thorax 1998, 53:204-212.

46. Martin BW, Ackermann-Liebrich U, Leuenberger P, Kunzli N, Stutz EZ, Keller R, Zellweger JP, Wuthrich B, Monn C, Blaser K, Bolognini G, Bongard JP, Brandli O, Braun P, Defila C, Domenighetti G, Grize L, Karrer W, Keller-Wossidlo H, Medici TC, Peeters A, Perruchoud AP, Schindler C, Schoeni MH, Villiger B: SAPALDIA: methods and participation in the crosssectional part of the Swiss Study on Air Pollution and Lung Diseases in Adults. Soz Praventivmed 1997, 42:67-84.

47. Jaakkola JJ, Jaakkola N, Ruotsalainen R: Home dampness and molds as determinants of respiratory symptoms and asthma in pre-school children. J Expo Anal Environ Epidemiol 1993, 3(Suppl 1):129-142.

48. Coultas DB, Peake GT, Samet JM: Questionnaire assessment of lifetime and recent exposure to environmental tobacco smoke. American journal of epidemiology 1989, 130:338-347.

49. Ronchetti R, Bonci E, de Castro G, Signoretti F, Macri F, Ciofetta GC, Villa MP, Indinnimeo L, Martinez FD: Relationship between cotinine levels, household and personal smoking habit and season in 9-14 year old children. Eur Respir J 1994, 7:472-476.

doi:10.1186/1465-9921-11-11

Cite this article as: Tsai et al:: Household environmental tobacco smoke and risks of asthma, wheeze and bronchitic symptoms among children in Taiwan. Respiratory Research 2010 11:11.

\section{Submit your next manuscript to BioMed Central and take full advantage of:}

- Convenient online submission

- Thorough peer review

- No space constraints or color figure charges

- Immediate publication on acceptance

- Inclusion in PubMed, CAS, Scopus and Google Scholar

- Research which is freely available for redistribution

Submit your manuscript at www.biomedcentral.com/submit
Biomed Central 